\title{
Stakeholder involvement in climate assessment: bridging the gap between scientific research and the public
}

\author{
Robert E. O'C onnor ${ }^{1, *}$, Patti J. Anderson², Ann Fisher ${ }^{3}$, Richard J . Bord ${ }^{4}$ \\ ${ }^{1}$ Department of Political Science, ${ }^{2}$ Environmental Resources Research Institute, ${ }^{3}$ Department of A gricultural Economics and \\ Rural Sociology, and ${ }^{4}$ Department of Sociology, The Pennsylvania State University, University Park, Pennsylvania 16802, USA
}

\begin{abstract}
Stakeholder participation is a crucial component of the M id-Atlantic Regional Assessment (MARA) of Possible Consequences of Climate Variability and Change. We involved stakeholders for 6 reasons: to ensure that the assessment addresses stakeholder concerns, to enhance the technical quality of the assessment, to provide a forum for stakeholders with diverse constituencies to share ideas, to facilitate dissemination of assessment findings, to sensitize stakeholders to possible impacts as well as adaptation strategies, and to legitimize the process to third parties. The key means for involvement is an Advisory Committee that represents a myriad of experiences and perspectives, including members from mining companies, non-governmental voluntary organizations, and government as well as researchers. In the first phase members attended workshops and, approximately bimonthly, received (via e-mail, fax, or regular mail) updates on the MARA team's progress, with a request for feedback on items such as work plans for specific topics (e.g., forestry, coastal zones), outlines of working group reports, draft scenarios that would serve as the basis for assessing impacts, or early materials for the draft preliminary report. Stakeholder involvement affected the focus of the assessment and the quality of the report. Stakeholders modified the M ARA focus to include concerns that might have been ignored and improved the technical analysis of possible impacts.
\end{abstract}

KEY WORDS: Stakeholders · Climate change $\cdot$ Regional assessment $\cdot$ M id-Atlantic states

\section{INTRODUCTION}

Stakeholder participation is a crucial component of the Mid-Atlantic Regional Assessment (MARA) of Possible Consequences of Climate Variability and Change. This paper discusses the reasons for involving stakeholders, MARA's experience, and lessons for future work. In one sense, everyone in the region is a stakeholder in the MARA project because all of the region's citizens could be affected by climate change. In identifying stakeholders to participate in the assessment process, the MARA research team is paying special attention to groups likely to be particularly affected by climate change (e.g., communities vulnerable to sea-level rise), researchers whose work is relevant to climate change, and to groups that have expressed an interest in the issue.

*E-mail: equipoise@psu.edu
Before turning to reasons for involving stakeholders, we need to describe the context for the assessment. Stakeholder processes in environmental policy work best when designed to accomplish specific goals tied to specific contexts (Y osie \& Herbst 1998, p. 15). We highlight 3 elements of the assessment's context.

First, as described elsewhere in this Special, the primary goal of the first phase's assessment was to produce a scientific document that reports the potential consequences of climate variability and change in the Mid-Atlantic Region (MAR). The need to produce a document and the short time available to do the work both focused stakeholder involvement on the document-production process and bounded opportunities. The MARA research team's approach to stakeholder involvement was to organize an Advisory Committee that would maintain ongoing communications through e-mail, facsimile, telephone and regular mail as well as meet twice with the MARA research team. The affilia- 
Table 1. Risk estimates (\%) of MAR residents. Ns vary from 276 to 284 with missing data. Actual wording: 'How likely do you think it is that average annual temperatures will increase by 3 degrees Fahrenheit within the next 50 years?' 'In your judgment, how likely are you, sometime during your life, to experience serious threats to your health or overall well-being from each of the following? (global warming)' 'In your judgment, how likely is it that each of the following (global warming) will have extremely harmful long-term impacts on our society?'

\begin{tabular}{|c|c|c|c|c|c|}
\hline & \multicolumn{2}{|c|}{$\begin{array}{l}\text { Not very } \\
\text { likely }\end{array}$} & \multirow[b]{2}{*}{3} & \multicolumn{2}{|c|}{$\begin{array}{l}\text { Very } \\
\text { likely }\end{array}$} \\
\hline & 1 & 2 & & 4 & \\
\hline That average temperature will increase by $3^{\circ} \mathrm{F}$ within the next $50 \mathrm{yr}$ & 15 & 12 & 32 & 17 & 25 \\
\hline That you will experience serious threats to your health or overall well-being from global warming & g 21 & 26 & 29 & 17 & 8 \\
\hline That global warming will have extremely harmful long-term impacts on our society & 10 & 16 & 25 & 25 & 25 \\
\hline
\end{tabular}

tions of most members of the Advisory Committee are citizen groups, business and industry, or state and local governments and commissions. Some members of the Advisory Committee are researchers, either with the national government or universities.

Second, at least in 1997, public opinion about climate change in the region was dominated by ambivalence and uncertainty. ${ }^{1}$ Although public opinion was decidedly mixed, more people were concerned than unconcerned about risks to society from climate change. Table 1 shows that many people were in the middle category, which usually indicates ambivalence and uncertainty. The modal category is that middle category for questions about whether people think there will be global warming and whether they will experience serious threats to their own health or overall wellbeing from global warming. It is likely that public opinion is still divided among a minority certain that the threat is real, an even smaller minority certain that the threat is bogus, and the largest group of skeptics looking for more certainty. There is evidence, however, that the debate over the Kyoto accords has had a somewhat polarizing impact on public opinion (Krosnick et al. 1998). Regarding whether society will suffer extremely harmful, long-term impacts from global warming, half the MAR respondents are on the 'likely' side in Table 1 . Yet, only $9 \%$ of those sampled consider themselves well informed about climate change and misinformation is widespread (O'Connor et al. 1998). Uncertainty combines with high risk perceptions to suggest that the public is likely to be receptive to climate change information, especially when that information is about possible impacts close to home.

\footnotetext{
${ }^{1}$ The data here are responses from a national survey, but restricted to residents of MAR states. Geographic clustering methods were not used for sample selection in the national study. Therefore, the results for the MAR sample may be viewed as derived from a random sample. See Bord et al. (1998, p. 76) for details on the survey and evidence that these findings tend to be similar across locations and time periods
}

Third, environmental interest groups argue that the evidence for climate change is so convincing that the government should move ahead immediately with strong policies to reduce greenhouse gas emissions. Other interest groups, representing the coal and oil industries, large utilities, farmers, and manufacturers, argue that more research is needed before action should be considered. Although the purpose of the MARA project is neither to endorse nor to reject specific government policies, stakeholder involvement inevitably will be influenced by the contentious nature of 'climate change' as a symbol as well as a scientific phenomenon.

\section{WHY INVOLVE STAKEHOLDERS? THE GOALS OF STAKEHOLDER IN VOLVEMENT}

The cynical answer to the origins of stakeholder participation would be that the US Environmental Protection Agency, which funds MARA, requires that the assessment involve stakeholders. Such a response, however, would be both incomplete and misrepresent the spirit with which the MARA team has undertaken its stakeholder involvement program. We started with the expectation that our core research team and stakeholders have differing strengths, and that sharing information through 2-way communication would contribute to a better assessment that would be more useful to a wide range of stakeholders. We identify 6 reasons for involving stakeholders in the regional assessment:

(1) To ensure that the assessment addresses stakeholder concerns. Even without the temporal and financial limitations MARA faces, it is impossible to assess every possible impact of global change in the MAR. Thus priorities must be set regarding which impacts will be assessed at all and which impacts will receive more in-depth assessment. One measure of an assessment's quality is whether it includes potential impacts of particular concern to stakeholders. The only 
way to identify those concerns is to communicate with stakeholders.

(2) To enhance the technical quality of the assessment. If there are gaps or biases in the methods or data sets used in the assessment, the team needs to identify these weaknesses early to allow time for reanalysis. Stakeholders include scientists as well as citizens untrained in technical disciplines. In particular, stakeholders sometimes know about or have access to data otherwise not available to the core assessment team.

(3) To provide a forum for stakeholders with diverse constituencies to share ideas. Meetings of the Advisory Committee provide a non-adversarial setting for members from diverse constituencies and backgrounds to share ideas. By focusing on the science and the process of the assessment, stakeholders may even discover unexpected areas of common interest.

(4) To facilitate dissemination of assessment findings. Stakeholders help with dissemination both by informing their own constituencies and by advising MARA regarding dissemination strategies such as public information opportunities.

(5) To sensitize stakeholders to possible impacts as well as adaptation strategies. Participation in the MARA process should sensitize stakeholders to both positive and negative potential impacts related to climate change in the MAR and to options that would take advantage of opportunities or cope effectively with damage.

(6) To legitimize the process to third parties. Broad stakeholder involvement enhances the credibility of the assessment process and its findings. Engaging a broad group of stakeholders makes it more difficult for critics to assert that the results would have been different if others had been included in the process.

\section{STAKEHOLDER INVOLVEMENT IN THE MARA}

The MARA team involved stakeholders even before beginning the assessment work in 1998. The group that was to become the MARA team convened a September 1997 workshop at Penn State to discuss available information about potential impacts from climate change for the watersheds of the Chesapeake Bay and the Delaware River Basin. The participants included both researchers and representatives of groups likely to be particularly affected by climate change. Participants identified issues that would deserve special attention in an assessment of potential regional impacts from climate change.

One group of stakeholders is the community of climate change researchers. Researcher members of the Advisory Committee include both natural scientists
Table 2. Advisory Committee members

$$
\begin{aligned}
& \text { Citizen groups } \\
& \text { Business and industry } \\
& \text { State and local governments and commissions } \\
& \text { Federal government researchers } \\
& \text { Academic researchers } \\
& \text { Total }
\end{aligned}
$$

25

19

22

13

13 and scholars who study human dimensions. As soon as receiving a go-ahead for the assessment, we convened a J une 1998 meeting at Penn State. Working for universities and government agencies, these researchers provided a state-of-the-art explanation of resources (e.g., data sets, studies, expertise) available to the MARA team for the assessment. This meeting also included formal and informal interchanges regarding the structure and process of the assessment.

Researchers, however, are only one component of the stakeholders for climate change in the MAR. As noted above, stakeholders range from the region's citizens, all of whom could be affected by climate change, to many people outside the region, who could be affected indirectly by changes in the region. Such a broad definition, however, is not helpful in forming an Advisory Committee that is small enough to focus constructively on a set of important issues yet large enough to represent the groups likely to experience substantial impacts in the region. We decided to pay special attention to groups likely to be particularly affected by, or that have expressed interest in, climate change. The MARA Advisory Committee represents a myriad of experiences and perspectives, including members from mining companies, non-governmental voluntary organizations, and government as well as researchers. Table 2 reports the distribution of Advisory Committee members.

The process of selection was informal and broad. We identified individuals and groups that had expressed great skepticism about global warming as well as those that support actions to reduce greenhouse gas emissions. Our greatest efforts went into recruiting representatives from business and industry to ensure that those sectors would be represented on the Advisory Committee. Still, every individual who sought to participate has had an opportunity to join the Advisory Committee.

For reasons of size and manageability, we decided not to invite elected officials to join the Advisory Committee. Climate change is a contentious political issue that has become partisan in some bodies. If we were to have invited one state legislator, one county commissioner, and one member of Congress, we would have felt obliged to ask all state legislators, 
county commissioners, and members of Congress in the MAR to participate. Certainly most would have declined our invitation, but we feared that a substantial number might have agreed to join or asked a staff member to work with us. We wanted to make certain that the composition of the Advisory Committee would be primarily private citizens, not government officials. $^{2}$

The full Advisory Committee met at Penn State October 19-20, 1998, and M ay 2-3, 1999. The members helped refine research questions at the October meeting. For example, participants expressed concerns about the implications of climate change for insurance coverage and the insurance industry. A general recommendation from the Advisory Committee encouraged the team to address issues of uncertainty as clearly and comprehensively as possible.

Approximately bimonthly, the Advisory Committee members received (via e-mail, fax, or regular mail) updates on the MARA team's progress, with a request for feedback on items such as work plans for specific topics (e.g., forestry, coastal zones), outlines of working group reports, draft scenarios that would serve as the basis for assessing impacts, or early materials for the draft preliminary report. Input also was solicited from them to identify priorities among agenda items for Advisory Committee meetings.

At the $M$ ay meeting stakeholders provided feedback on the draft preliminary assessment and offered advice about displaying findings, developing materials, and disseminating the assessment results to a wide audience. Their suggestions also were used to hone plans for the second phase's assessment activities.

A number of individuals want to provide input but are unable to participate as fully as described above. These individuals provide somewhat less extensive feedback to assessment designs and documents by email, phone, and mail, as corresponding members of the Advisory Committee.

In addition to coming together for working meetings and reviewing draft documents, many Advisory Committee members have maintained informal communications with team members working on particular parts of the report. This 2-way communication both enhances the quality of the assessment report and ensures that stakeholders understand how their participation makes a difference in the assessment process.

\footnotetext{
2In retrospect, we understand that inviting state, regional, or national associations of elected officials (e.g., The Pennsylvania Association of County Commissioners) to participate might have provided representation without unduly increasing the size of the Advisory Committee
}

The MARA team has not depended entirely on the Advisory Committee to communicate with stakeholders. To accomplish the goals for stakeholder involvement, the MARA team uses multiple methods including a site on the World Wide Web (http://www. essc.psu.edu/mara/). This web site serves as a source of information and encourages discussion. Presentations at scholarly conferences and articles in journals publicize the work in the researcher community. Still, much of our stakeholder interaction continues in the context of the Advisory Committee.

\section{AN INFORMAL EVALUATION}

Section 2 listed 6 goals of stakeholder involvement. At this stage of the MARA, we are able to comment on the first 3 goals (address concerns, enhance technical quality, provide a forum). The second 3 goals (disseminate results, sensitize stakeholders, legitimize the process) await evaluation during and after the second phase's assessment.

To ensure that the assessment addresses stakeholder concerns. We are confident that the assessment document, Mid-Atlantic Regional Assessment (MARA) Draft Preliminary Report on Impacts of Climate Change (Fisher et al. 1999), addresses stakeholder concerns for 2 reasons: stakeholders told us that the analysis plan and the draft document reflect their concerns, and we changed the focus of the assessment to respond to their recommendations.

At the October 1998 meeting stakeholders reviewed the preliminary analysis plan and suggested additional emphases. At the M ay 1999 meeting they reviewed the draft document. In between those meetings we used email, facsimile, and phone communications to ask stakeholders if the work was addressing their concerns. The stakeholders told us that we were on track.

At different stages in the assessment process some stakeholders did tell us we needed to attend more to certain topics. As a result, stakeholder involvement changed the substantive content of the assessment. Even before the assessment period began, at the September 1997 workshop, we learned that stakeholders had a great deal of concern about potential health impacts. Much less attention would have been paid to health effects without their expressed concern about this issue. At the October 1998 meeting we learned that stakeholders wanted us to pay more attention to potential impacts on insurance and the insurance industry. In response, we modified research plans for 3 sections of the assessment. In M ay 1999 stakeholders said they wanted to know more about impacts on recreation and tourism, although they recognized that 
data are not gathered in a way that is especially helpful. In response, we prepared a recreational baseline and are doing more in the second phase. Perhaps most importantly, we have heard throughout the process that the research team needed to address issues of the degree of certainty for all of the projections in the assessment. We have addressed this concern throughout the document.

To enhance the technical quality of the assessment. Advisory Committee members alerted us to sources of data, both archives and people, as well as to individuals who were able to participate in the writing of the report. In J une 1998 the MARA research team met with Advisory Committee members who are researchers. These experts played a pivotal role in the development of the assessment as a consequence of both what the MARA research team learned from them at the meeting and the relationships that began at the meeting. MARA research team members called upon these expert Advisory Committee members often. Numerous parts of the analysis would have been done differently (and not as well) without the input of the researcher contingent of the Advisory Committee. In summary, stakeholder involvement modified the MARA focus to include concerns that might have been ignored and improved the technical analysis of possible impacts.

To provide a forum for stakeholders with diverse constituencies to share ideas. Post-meeting surveys report a consensus among Advisory Committee members that they learn from documents and team members as well as from each other. They find the process productive not just to improve the report, but also to shape their own thinking. Although the Advisory Committee includes members with widely differing ideologies and opinions about climate change, discussions have been unfailingly civil and constructive as members focus on improving the assessment.

\section{NEXT STEPS}

One important success in stakeholder involvement for the first phase of the assessment may be establishing a base for ongoing assessment activities. One component for this base builds on the initial assessment finding that climate change has potentially significant ecological impacts. A next step is to develop and implement a process of selecting priorities for ecological assessment that involves the region's stakeholders and researchers. The task now is to devise procedures and methods for ascertaining how stakeholders think about ecological impacts from climate change and other stressors. What do they think should be the prior- ities for further assessment? Their answers to what they want us to assess would reflect their mental maps and values (Lazo et al. 1999). A key to understanding stakeholder perceptions may be how they see tradeoffs and options.

The process will involve 2 components: (1) researchers will work with stakeholders to identify ecological resources that may be at risk and (2) stakeholders will answer researchers' questions about which ecological resources are most highly valued and which risks are of most concern. The process will be iterative, with researchers refining the scope of their work in accordance with stakeholder values and with stakeholders refining their statements about their concerns as they learn how things that they value can be related to quantifiable ecological risks.

Improving methods for obtaining public and stakeholder views is an important task in the assessment process. There is a common assumption that people care most about big animals (charismatic mega-fauna). The Advisory Committee has convinced us that this is too simplistic, that how people think about the land and its ecosystems is complex and quite subtle. A method for the research might involve a 'snowball' approach that would look at the literature, speak with some key informants (e.g., regional planners, elected officials, EPA experts), conduct a series of focus groups with different groups (e.g., people who fish commercially, farmers, recreational anglers, developers, foresters), and then use what we have learned to design and implement a general survey in the region. The findings would pertain to this region, but the methodological advances would be useful for other assessments.

A second component for establishing a base for ongoing assessment activities builds on another major initial assessment finding: a storm of given intensity will do more damage in coastal areas because of sealevel rise. One of our private-sector Advisory Committee members has identified data and models that might be appropriate for more detailed assessment of potential storm damage, and offers organizational support. This is the sort of public-private partnership envisioned by the US Global Change Research Program as a way to continue and improve regional assessments.

\section{LESSONS LEARNED}

Stakeholder participation is an integral part of plans for the national assessment of climate change impacts and engaging stakeholders is an explicit goal of the MARA. One lesson is that the process of including stakeholders occasionally can surprise the organizers of the assessment effort. For example, we found sub- 
stantive interest among stakeholders for topics, such as human health, that had been a low priority for researchers. A second lesson is that responding to stakeholder input can ensure that the results and report provide useful information that links to the interests of people within our region. A third lesson is that we discovered, once again, that stakeholders provide a vital sounding board for clearer thinking and clearer expression of what the assessment shows as well as its gaps and uncertainties. Our research has depended, and our future reports will depend, on the interested and careful participation of our stakeholders to make sure what we say really makes sense.

Acknowledgements. We appreciate financial support from the US Environmental Protection Agency (Cooperative Agreement No. CR 826554) and the National Science Foundation (Grant SRB-9409548). The views expressed are the authors' and should not be attributed to their employer or funding sources.

\section{LITERATURE CITED}

Bord RJ , Fisher A, O'Connor RE (1998) Public perceptions of global warming: United States and international perspectives. Clim Res 11:75-84

Fisher A and 12 others (1999) Mid-Atlantic Regional Assessment (MARA) draft preliminary report on impacts of climate change. Prepared for USGCRP First National Assessment, sponsored by US Environmental Protection Agency, Cooperative Agreement CR 826554-01 (accessed: 1 October 1999); available at http://www.ess.psu/mara/ data.html\#draft_documents

Krosnick J A, Visser PS, Holbrook AL (1998) American opinion on global warming: the impact of the fall 1997 debate. Resources 133:5-9

Lazo J K, Kinnell J , Bussa T, Fisher A, Collamer N (1999) Expert and lay mental models of ecosystems: inferences for risk communication. Risk Health Safety Environ 10(1): 45-64

O'Connor RE, Bord RJ , Fisher A (1998) The curious impact of knowledge about climate change on risk perceptions and willingness to sacrifice. Risk Decision Policy 3:145-155

Yosie TF, Herbst TD (1998) Using stakeholder processes in environmental decisionmaking: an evaluation of lessons learned, key issues, and future challenges. Tec-Con Inc, Knoxville TN (assessed: March 2000); available at: http:// www.riskworld.com/N reports/1998/STAKEHOLD/HTML/ nr98aa01.htm 